\title{
REVIEWING SEISMIC VULNERABILITY DIMENSIONS: CURRENT TRENDS AND METHODOLOGICAL CHALLENGES
}

\author{
LUIS IZQUIERDO-HORNA \& YUSTIN YEPEZ \\ Universidad Tecnológica del Perú, Peru
}

\begin{abstract}
Traditionally, seismic vulnerability has been assessed considering, for the most part, infrastructure as the main evaluation component, leaving aside other dimensions of study. This result does not adequately evaluate all the anthropogenic characteristics that make a certain system more susceptible to experiencing economic, patrimonial, and human losses in the face of natural phenomena. In this context, Peru is exposed to many different phenomena of the earth's internal and external geodynamics (i.e., earthquakes, tsunamis, volcanism, mass movements, heavy rains, drought, etc.), earthquakes being the ones that have caused the most damage and repercussions. It is for the latter, considering that seismic hazards are determined by the geographical conditions of the study area, that the main objective of this review is to study and highlight different perspectives of vulnerability analysis (i.e., social, cultural, economic, etc.) when seismic events happen. This review shows the main assessment parameters used to describe each dimension of analysis and in addition, a review of the main existing methodological frameworks is carried out, aimed at showing a comprehensive perspective of the context analyzed in order to improve the conditions and livelihoods of the population exposed to these hazards.

Keywords: seismic vulnerability, vulnerability dimensions, earthquakes, risk and disaster management, Peru.
\end{abstract}

\section{INTRODUCTION}

Peru is exposed to many different events of natural origin due to its multiple geographical interactions [1]. In addition, it is located in a demarcation of high seismic movement caused by the subduction process between the Nazca oceanic plate that moves under the South American continental plate, causing these geological phenomena to be severely recurrent [2].

Throughout history, there have been several earthquakes of great magnitude. According to the historian Silgado Ferro [3], one of the oldest and most devastating earthquakes on record occurred in 1604 with a magnitude of 8.4. It was originated in the southern coast of Peru and affected the cities of Arica, Tacna, Moquegua, Arequipa, extending to Ica, being perceived up to $130 \mathrm{~km}$ from the coast inland and 1,650 km (approximately) from north to south, causing 23 human losses in the Port of Pisco. Later on, other seismic events, also of great magnitude, would occur in 1784 (magnitude of 8.1 in Arequipa, 54 deaths, 500 injured and countless buildings destroyed), 1868 (magnitude of 8.6 in Moquegua, where 300 aftershocks were counted, 150 deaths), 1942 (magnitude 8.4, in the border region of Ica and Arequipa, 30 people died due to houses collapsing and 25 were injured due to many different reasons) [4], and in 1970 (magnitude 7.8 and a large flood in Callejón de Huaylas, Ancash, 67,000 people died and 150,000 were injured). In recent times, the 2007 earthquake on the central coast and with a magnitude of 7.9 caused significant damage, especially in Pisco (considered the epicenter and where damage was generated to approximately $80 \%$ of the structures), minor damage was also caused in towns near the coast [5]; but mainly it caused several -and very sad- human losses. These events not only generate material damages and significant human losses, they also interrupt different business activities (i.e. social, economic, community development, infrastructure and public resources) of a community [6]. 
In this context, factors associated with sustainable development increase the destructive effects of earthquakes, since they are enhanced by the disorderly growth of cities, it is because of this that it is important to study what makes a certain community susceptible - or not - to experiencing large or few losses; that is, they are more vulnerable compared to their peers. In this sense, Adger [7] states that the study of vulnerability faces important challenges in different human dimensions, in which a solid conceptual framework must be included, addressing perceptions of vulnerability and governance. Currently, the studies carried out on seismic vulnerability should not only focus only on quantitative approaches, but also on qualitative ones, on methods capable of translating the abstract concept of vulnerability into practical tools, classifications and comparative criteria through demographic, social, economic, environmental, and institutional factors [8], [9].

On the other hand, studies are usually based on factors related to infrastructure in Peru; however, there are more elements (i.e., social, economic, cultural, resilience, etc.) that need to be further explored [10], therefore, the purpose of this review is to assess the descriptive potential of the main indicators used for each analysis dimension. In addition, a complete description of the methodological proposals for seismic vulnerability is offered, integrating their assessment. Lastly, this review carries out a systematization of the information, using a hierarchical analysis process of the results obtained from the seismic vulnerability evaluations available in the literature.

\section{MAIN PARAMETERS USED FOR THE ASSESSMENT OF SEISMIC VULNERABILITY}

The concept of "vulnerability assessment" not only includes quantitative approaches, it also seeks discussing and developing all kinds of methods capable of translating the abstract concept of vulnerability into practical tools that work as support for decision-making [9]. Likewise, determining the physical, social, economic and environmental parameters are the starting point to mitigate risk and promote a culture that is resilient to disasters [11]. At the global level, in order to represent the vulnerability context of a community, different contexts were analyzed to determine relevant indicators. Typically, these indicators are based on the geographic environment of the disaster, pre-existing social, economic and political conditions, hazard characteristics, degree of exposure, impact and response scales, and the disaster phase (i.e. before, during, after) [12].

Due to the multiple nature vulnerabilities and complexities that occur in our country, Peru, parameters (i.e. social, economic and environmental) were proposed in order to be taken into account and integrate them into criteria for prevention and reduction of risks in the various land use planning processes, planning, investment and environment management programs for each specific sector [10].

\subsection{Socioeconomic dimension}

This dimension is important to assess because it is inversely related to vulnerability, that is, the less privileged sectors suffer the greatest losses due this type of phenomenon occurring and also have a limited capacity for recovery [13]. The socioeconomic dimension can be defined as the probability of being below the poverty line at a time of chaos [9]. In this sense, in China, the percentage of the low-income population and the percentage of the population aged 15 years and over that possess an education degree below a high school diploma were analyzed [6]. Along the same lines, in Indonesia the debt and lack of productive assets in women were analyzed [14]. In Malaysia, parameters such as: gross income and gross domestic product (GDP) were considered [15]. Likewise, in Uttarakhand (India) they were 
based on the poverty rate, agricultural workers and the unemployed [16]. Similarly, in Colombia and Mexico, certain parameters were studied such as: average economic income, economic loss, minimum or total intervention costs, and interruption costs [17], [18]. In the United States, they used parameters such as: personal wealth, economic dependence on a single sector, and occupation [8], [19]; the percentage of households that could seek temporary shelter after an earthquake and the total economic cost required for the replacement, reconstruction, and recovery of residential buildings were also analyzed [20]. In the case of Italy, the following were considered: occupational separation rate, employed female labor force, employed labor force, and unemployment and employment rate [21], [22]: and in Portugal, parameters such as unemployment rate and social dependency rate were also used [23], [24].

At the national level, the dependent population, daily personal income and permanent disability were studied [25]. In addition, in Pisco parameters such as: unemployment, insufficient income, employment instability, difficulty and total impossibility to accessing formal education, recreation and health services were used [2]. Lastly, CENEPRED [10] proposed a list of economic parameters in order to contextualize aspects related to the person and the built environment.

\subsection{Sociocultural dimension}

The sociocultural dimension establishes the link between the population and its environments with social and institutional relations, population concentration, level of poverty, level of human development, cultural values, among others. It also includes factors related to social equity, access to basic human rights, systems of collective organization, levels of ability to read and write, education, existence of peace and security, systems of good governance, traditional values, customs, and ideological beliefs [13]. Likewise, Ngo [26], states that variations within the elderly population, such as gender, marital status, race, education and religion, can affect the type of vulnerability of the population when facing a natural disaster. Historically ingrained patterns of discrimination and social relationships, inequitable access to resources and power are important determinants of vulnerability [9]. At the international level, in Southeast Asia they used parameters such as: age, education and ethnicity [27], gender, disability status, illiteracy [28] and migration [29].

In this sense, in Indonesia they considered the following parameters: homeless women, violence against women, widows with dependents, female heads of the household, and sexual abuse to women [14]. Likewise, in Manzanillo (Mexico) parameters such as: level of education, knowledge, perception of the individual, historical knowledge, informality of the neighborhood, informality of housing, existence of prevention plans, and community response were used [18]. Also, the United States, Romania and Turkey used parameters such as: race, ethnicity [30], age, education, inventory and housing ownership, and dependency on infrastructure [8], [31], [32]. In addition, in Italy, Portugal and the Netherlands they used parameters such as: age, gender, family structure [24], education, employment, race and ethnicity [21], [33], population density, foreign residents, and social cohesion [22].

At the national level, the following indicators were proposed: education level, age profile, permanent disability, and family structure [25]. In addition, in Huaraz they used social factors such as: population with primary education, population with higher education, illiterate population, indigenous population, population over 65, women, informal settlement, population with disabilities, population with health insurance, etc. [34]. 


\subsection{Sociodemographic dimension}

The demographic dimension is related to the population groups that are affected by similar circumstances that limit their capacities for self-sufficiency [18].

Internationally, indicators such as the percentage of the female population, the percentage of the elderly population, the gross birth rate, and the percentage of the population with physical and mental disabilities were used [6]. In this sense, parameters such as: population density, household density [15] and dependency rate [27], [28] were also used. Similarly, in Iran they based their parameters on the density of the child population, the density of the elderly population, the density of the female population, the population density at the educational level, and the population density of the employment situation [35]-[37]. In Manzanillo (Mexico), they used parameters such as degree of population concentration, dependent population, and installed anthropic activity [18]. Also in the United States, they used parameters such as density of the built environment, children population and elderly population [8], percentage of immigrant population, percentage of institutionalized elderly population, percentage of black population, and percentage of Hispanics [19]. It should be noted that, even in the Netherlands, single-parent households were considered as a parameter [33].

At the national level, the following demographic indicators were proposed: access to basic medical services and anthropogenic activity [25]. On the other hand, in Acobamba (Carhuaz, Ancash) parameters related to urban planning, business planning, natural resource management, risk and emergency assessment, environmental impact, service management, transportation routes, cartography, and sociological and demographic studies were used [38]. Lastly, in Pisco the following were used: children population and elderly population [2], [39].

\subsection{Environmental dimension}

The United Nations [40] state that the environmental dimension refers to the degradation degree of nature and its resources, and climate change. In addition, they point out that parameters such as decrease in biodiversity, poor sanitation, air and water pollution, water scarcity and soil degradation, increase the vulnerability of a population. Often, in the long term, environmental changes lead to increased morbidity, premature death and a reduction in the quality of life [26]. In this sense, Birkmann and Wisner [9] propose two points of view, the first one is to focus on the susceptibility and fragility of ecosystems and the environmental components themselves, and the second one considers the interruption of environmental services that are essential for human wellbeing. Along these lines, in the mountainous land of Uttarakhand (India), parameters such as: percentage of forest cover area, forest fires, percentage of wasteland and percentage of landslide area out of the total area, were used [16]. On the other hand, in Sanandaj (Iran) environmental parameters were proposed (i.e. road distance, distance from a fault, slope, elevation and geology) concluding that they increase the impact on the earthquake risk assessment [36].

Lastly, in Peru the following environmental parameters were proposed: soil loss, soil geological characteristics, deforestation, species of flora and fauna by geographic area, water loss, exploitation of natural resources, etc. [10].

\subsection{Physical dimension}

The physical dimension refers to the susceptibility of the constructive or natural environment of the population when facing hazards [13]. 
Internationally, in Dhaka (Bangladesh) they used parameters such as usage and size of the building, land area, photograph of the building, and construction and elevation plans [28]. Likewise, in Uttarakhand (India) they used: proximity to the river, frequency of floods and average rainfall in the last 50 years [16]. In that sense, in Iran they used parameters such as the age of the building, type of structure, floor number [41]-[43], quality of construction materials, coefficient of seismic resonance [35] and land use [36]. Similarly, in Los Angeles (United States) they were based on criteria such as the area of land that could be burned due to an induced fire and the amount of debris measured in thousands of tons [20]. Along these lines, in Vaslui (Romania) they were based on factors such as: age of the building, construction material, number of floors, number of exits, etc. [44]. Similarly, in Turkey, Italy and Portugal, factors associated with the structure were used, such as the position and structural system of the stairs, the width and natural lighting of the evacuation route, irregularities and interaction, floors and roofs, etc. [23], [24], [32], [45], [46].

At the national level, in Cusco they used factors such as: typology of buildings, type of structure, thickness of facade, among others [47]. Similarly, in the district of Punta Negra (San Bartolo, Lima) they used parameters such as number of floors, predominant structural system, type of building material, etc. [48]. Lastly, in Pisco they were based on: damage to the building, maximum rates of soil movement, and fragility of derivatives [49].

\section{METHODOLOGICAL APPROACHES APPLIED TO THE ASSESSMENT OF SEISMIC VULNERABILITY}

\subsection{Machine learning approaches}

Nowadays, many researchers have tried to use machine learning to integrate many objective algorithms to reduce the margin of error. However, this approach is not as common in seismic vulnerability assessment. Thus, in Tehran (Iran), a brand new machine learning was used that evaluated seismic vulnerability based on the analysis method of the relationship between the step-wise weight assessment ratio analysis (SWARA) and the geographic information system (GIS), achieving that users with little knowledge in the area can easily determine seismic vulnerability [35].

\subsection{GIS and other assessment approaches}

The GIS approach is the most used by researchers because it helps generating a vision of who is vulnerable and in which locations, which allows the implementation of specific impact reduction strategies.

Internationally, in the case of Portugal, seismic vulnerability was analyzed with social and physical factors by analyzing multi-criteria decisions in a GIS environment [23], [24], [46]. Likewise, in Italy, through integrated indices, seismic vulnerability was assessed in a GIS environment [22], [45]. Similarly, in Vaslui (Romania) seismic vulnerability was studied through a hierarchical analysis process in a GIS environment [44]. In addition, in Southeast Asia and the Middle East, to reduce disaster risk, social vulnerability was assessed through multi-criteria analysis integrated in a GIS environment [15], [27], [28], [37]. Also, in Los Angeles (United States) the vulnerability of urban areas towards seismic hazards was assessed using the fuzzy logic approach and multi-criteria spatial analysis in a GIS environment [20]. 
At the national level, in Peru, micro zoning maps were made to assess physical and social vulnerability towards natural disasters through a multi-criteria analysis in a GIS environment [10], [25], [38], [47], [48], [50].

\subsection{AHP approaches}

The Analytic Hierarchy Process (AHP) approach allows managing the subjectivity of the judgment associated with the weighting of the estimation of the vulnerability parameters through the construction of a comparison matrix, allowing the reduction of uncertainty and error that exist in the assessing process [20], [23], [24], [28], [29], [35], [36], [42], [43], [51].

\subsection{Principal component analysis: PCA}

The Principal Component Analysis (PCA) approach describes a data set in terms of new uncorrelated parameters using multivariate analysis. In this sense, in Manzanillo (Mexico) it was proposed to work through principal component analysis with composite indicators of the different levels of vulnerability of the population when natural disasters occur [18]. Likewise, in the United States, indices for social vulnerability due to earthquakes were formulated for different magnitude levels through principal component analysis [19], [30]. Furthermore, in Europe parameters of social vulnerability to natural disasters were identified through principal component analysis [24], [31], [33]. Along the same lines, to mitigate disaster risk, in Central Java (Indonesia) social vulnerability was assessed through principal component analysis [27]. Similarly, in Iran, the ratios of social vulnerability to disasters were adequately classified with the principal component analysis [29]. Also, in Huaraz (Peru), to calculate the response time in evacuations, a social vulnerability index was created through the principal component analysis [34].

\section{CONCLUSIONS AND RECOMMENDATIONS}

In general terms, the studies analyzed suggest that assessing vulnerability to seismic events requires a broad approach that analyzes and includes all the parties involved, that is, people and the built environment, since a partial approach only composes a vision biased from the problem to be addressed, which causes - in turn - partial solutions in the short, medium and long term. In fact, the studies suggest analyzing many different dimensions that allow the evaluator to understand the situational reality and the context in which the events are taking place. Hence, the results validate the importance of conducting studies with more diverse approaches that collect a greater amount of information so that the exposed population can be segmented much better. For example, dimensions such as those related to the cultural aspect, take on special relevance when it comes to understanding the many conceptions and representations of hazard or, even more so, when trying to understand the link between the worldviews of the population and the events per se. In fact, it is expected that the dimensions described in this document work as support information to generate more exhaustive studies when assessing seismic vulnerability. On the other hand, when comparing the analyzed studies, it was observed that -in some cases- different parameters were obtained during the seismic vulnerability assessment for similar dimensions. These differences are related to the availability of information on the sector and the kind of work technique. Furthermore, most of the studies did not perform any uncertainty or sensitivity analysis. Thusly, comparisons should be made with caution, bearing in mind that the statistical approaches applied will tend to provide better results as better quality of the database is available. 
In general, there has been progress in terms of vision and methods to determine the level of seismic vulnerability in a given case study in recent years. For example, Izquierdo-Horna and Kahhat [52] show how the level of vulnerability to seismic events varies for a Peruvian case study when the social dimension is taken into consideration. This research shows the importance not only of the inclusion of a human development approach but also of the importance of the integration approach between various dimensions (i.e., socioeconomic dimension, sociocultural dimension, sociodemographic dimension, environmental dimension and physical dimension). This integrated and articulated approach facilitates decision making, since the affected population takes on a leading role in the subsequent evaluation of seismic risk, becoming a social agent [8], [9]. This scenario allows dealing with social incommensurability [7]. Finally, at the national level, it is important to mention that although the guidelines and regulations provided by CENEPRED have undergone updates in the evaluation of vulnerability, giving more emphasis to the person through its social, cultural and environmental dimensions, there is still a significant gap to overcome in terms of study techniques, sources of information and characterization factors [1]. To conclude, we hope that this review of seismic vulnerability assessment will serve as a basis for future studies to consider including as many dimensions as possible in order to have a more complete view of the area of interest.

\section{ACKNOWLEDGEMENT}

This project was funded by Universidad Tecnológica del Perú, within the framework of the "Research Projects I+D+i 2021-1" agreement.

\section{REFERENCES}

[1] CENEPRED, Manual para la evaluación de riesgos originados por Fenómenos Naturales v3.0, Lima, 2019. https://cenepred.gob.pe/web/wp-content/uploads/Guia Manuales/Borrador EVAR V3/MANUAL_EVARv3-PRE.pdf.

[2] Llocclla, E., Evaluación del riesgo sísmico en los distritos de Ica, Parcona y La Tinguiña, 2005. http://sinpad.indeci.gob.pe/IntranetOracle/Documentos/Informe_ riesgos_sismico_Ica_parte1.pdf.

[3] Silgado Ferro, E., Earthquakes of the XVI and XVII centuries in Peru. Geogr. Soc. Lima; XCII, 1974. https://app.ingemmet.gob.pe/biblioteca/pdf/P-226.pdf.

[4] INDECI, Sismos ocurridos en e Perú a traves del tiempo. Compend Estadístico Prevención y Atención Desastr 2006 Sismos Ocurr en el Perú, 7, 2006.

[5] Tavera, H. \& Bernal, I., The Pisco (Peru) earthquake of 15 August 2007. Seismol. Res. Lett., 79, pp. 510-515, 2008.

[6] Lee, Y.-J., Social vulnerability indicators as a sustainable planning tool. Environ. Impact Assess. Rev., 44, pp. 31-42, 2014.

[7] Adger, W.N., Vulnerability. Glob. Environ. Chang., 16, pp. 268-281, 2006.

[8] Cutter, S.L., Boruff, B.J. \& Shirley, W.L., Social vulnerability to environmental hazards. Soc. Sci. Q., 84, pp. 242-261, 2003.

[9] Birkmann, J. \& Wisner, B., MEASURING the un-measurable: The Challenge of Vulnerability, 2006. http://www.ihdp.unu.edu/file/get/3962.pdf.

[10] CENEPRED, Manual para la evaluación de riesgos originados por Fenómenos Naturales, 2nd ed., Lima, 2014. https://www.cenepred.gob.pe/web/wp-content/ uploads/Guia_Manuales/Manual-Evaluacion-de-Riesgos_v2.pdf. 
[11] United Nations, Hyogo Framework for Action 2005-2015: Building the Resilience of Nations and Communities to Disasters. World Conf Disaster Reduct., 2005. https://www.unisdr.org/2005/wcdr/intergover/official-doc/L-docs/Hyogo-frameworkfor-action-english.pdf.

[12] Rufat, S. et al., Social vulnerability to floods: Review of case studies and implications for measurement. Int, J, Disaster Risk Reduct., 14, pp. 470-486, 2015.

[13] Ocola, L., Peligro, vulnerabilidad, riesgo y la posibilidad de desastres sísmicos en el Perú. Rev. Geofísica, 61, pp. 81-125, 2005.

[14] Yumarni, T., Amaratunga, D. \& Haigh, R., Assessing gender vulnerability within postearthquake reconstruction: Case study from Indonesia. Procedia Econ. Financ., 18, pp. 763-771, 2014.

[15] Suhaiza Sauti, N., Effendi Daud, M. \& Kaamin, M., Proposed method and framework for evaluating and calculating a seismic vulnerability index of Malaysia. IOP Conf. Ser. Earth Environ. Sci., 616, 012034, 2020.

[16] Kumar, D. \& Kumar Bhattacharjya, R., Study of integrated social vulnerability index (SoVI int) of hilly region of Uttarakhand, India. Environ. Clim. Technol., 24, pp. 105$122,2020$.

[17] Yamin, L.E. et al., Probabilistic seismic vulnerability assessment of buildings in terms of economic losses. Eng, Struct., 138, pp. 308-323, 2017.

[18] Thomas, J.E., Evaluación de la vulnerabilidad social ante amenazas naturales en Manzanillo (Colima): Un aporte de método. Investig. Geográficas, 81, pp. 79-93, 2013.

[19] Schmidtlein, M.C. et al., Modeled earthquake losses and social vulnerability in Charleston, South Carolina. Appl. Geogr., 31, pp. 269-281, 2011.

[20] Rashed, T. \& Weeks, J., Assessing vulnerability to earthquake hazards through spatial multicriteria analysis of urban areas. Int. J. Geogr. Inf. Sci., 17, pp. 547-576, 2003.

[21] Frigerio, I. \& De Amicis, M., Mapping social vulnerability to natural hazards in Italy: A suitable tool for risk mitigation strategies. Environ. Sci. Policy.,63, pp. 187-196, 2016.

[22] Azzimonti, O.L. et al., Combining hazard, social vulnerability and resilience to provide a proposal for seismic risk assessment. J. Risk Res., 23, pp. 1225-1241, 2020.

[23] Martins, V.N., Silva, D.S. \& Cabral, P., Social vulnerability assessment to seismic risk using multicriteria analysis: The case study of Vila Franca do Campo (São Miguel Island, Azores, Portugal). Nat. Hazards, 62, pp. 385-404, 2012.

[24] Fernandez, P., Mourato, S. \& Moreira, M., Social vulnerability assessment of flood risk using GIS-based multicriteria decision analysis: A case study of Vila Nova de Gaia (Portugal). Geomatics, Nat. Hazards Risk, 7, pp. 1367-1389, 2016.

[25] Izquierdo-Horna, L. \& Kahhat, R., Methodological framework to integrate social and physical vulnerability in the prevention of seismic risk. WIT Transactions on Engineering Sciences, pp. 69-79.

[26] Ngo, E.B., When disasters and age collide: Reviewing vulnerability of the elderly. Nat. Hazards Rev., 2, pp. 80-89, 2001.

[27] Wijaya, A.P. \& Hong, J.-H., Quantitative assessment of social vulnerability for landslide disaster risk reduction using gis approach (Case study: Cilacap Regency, Province of Central Java, Indonesia). Int. Arch. Photogramm. Remote Sens. Spat. Inf. Sci., 42(4), pp. 703-709, 2018.

[28] Rahman, N., Ansary, M.A. \& Islam, I., GIS based mapping of vulnerability to earthquake and fire hazard in Dhaka city, Bangladesh. Int. J. Disaster Risk Reduct., 13, pp. 291-300, 2015. 
[29] Fatemi, F. et al., Social vulnerability indicators in disasters: Findings from a systematic review. Int. J. Disaster Risk Reduct., 22, pp. 219-227, 2017.

[30] Hung, L., Wang, C. \& Yarnal, B., Vulnerability of families and households to natural hazards: A case study of storm surge flooding in Sarasota County, Florida. Appl. Geogr., 76, pp. 184-197, 2016.

[31] Armaş, I. \& Gavriş, A., Census-based social vulnerability assessment for Bucharest. Procedia Environ. Sci., 32, pp. 138-146, 2016.

[32] Yücel, G. \& Arun, G., Earthquake and physical and social vulnerability assessment for settlements: Case study Avcilar District. Megaron., 5, pp. 23-32, 2010.

[33] Koks, E.E. et al., Combining hazard, exposure and social vulnerability to provide lessons for flood risk management. Environ. Sci. Policy., 47, pp. 42-52, 2015.

[34] Hofflinger, A., Somos-Valenzuela, M.A. \& Vallejos-Romero, A., Response time to flood events using a social vulnerability index (ReTSVI). Nat. Hazards Earth Syst. Sci., 19, pp. 251-267, 2019.

[35] Lee, S. et al., SEVUCAS: A novel GIS-based machine learning software for seismic vulnerability assessment. Appl. Sci., 9, p. 3495, 2019.

[36] Yariyan, P. et al., Earthquake risk assessment using an integrated fuzzy analytic hierarchy process with artificial neural networks based on GIS: A case study of Sanandaj in Iran. Int. J. Disaster Risk Reduct., 50. DOI: 10.1016/j.ijdrr.2020.101705.

[37] Ahmad, R.A., Singh, R.P. \& Adris, A., Seismic hazard assessment of Syria using seismicity, DEM, slope, active faults and GIS. Remote Sens. Appl. Soc. Environ., 6, pp. 59-70, 2017.

[38] Lazaro, M.R., Nálisis de peligros y vulnerabilidades para la gestión del riesgo de desastres, utilizando el sistema de información geográfica (SIG) en la localidad de Acopampa - Carhuaz, Ancash. Tesis de Titulación, Universidad Nacional Santiago Antunez De Mayolo, 2015. http://repositorio.unasam.edu.pe/handle/UNASAM/1190.

[39] INDECI, Mapa de peligros, plan de usos del suelo y medidas de mitigación de la ciudad de Pisco, 2001. https://sigrid.cenepred.gob.pe/sigridv3/documento/5226/ descargar.

[40] United Nations, On better terms: A glance at key climate change and disaster risk reduction concepts, Switzerland, 2006. https://www.preventionweb.net/files/3854 Onbetterterms1.pdf.

[41] Sadrykia, M., Delavar, M. \& Zare, M., A GIS-based fuzzy decision making model for seismic vulnerability assessment in areas with incomplete data. ISPRS Int. J. GeoInformation, 6, p. 119, 2017.

[42] Delavar, M.R. \& Sadrykia, M., Assessment of enhanced Dempster-Shafer theory for uncertainty modeling in a GIS-based seismic vulnerability assessment model, case study: Tabriz City. ISPRS Int. J. Geo-Information, 9, p. 195, 2020.

[43] Karimzadeh, S. et al., A GIS-based seismic hazard, building vulnerability and human loss assessment for the earthquake scenario in Tabriz. Soil Dyn. Earthq. Eng., 66, pp. 263-280, 2014.

[44] Albulescu, A.-C., Larion, D. \& Grozavu, A., Multi-criteria assessment of the seismic vulnerability of school units in Vaslui city, Romania. WIT Transactions on Engineering Sciences, pp. 17-28.

[45] Chieffo, N., Formisano, A. \& Miguel Ferreira, T., Damage scenario-based approach and retrofitting strategies for seismic risk mitigation: An application to the historical Centre of Sant'Antimo (Italy). Eur. J. Environ. Civ. Eng., 8189, pp. 1-20, 2019.

[46] Vicente, R. et al., Seismic vulnerability and risk assessment: Case study of the historic city centre of Coimbra, Portugal. Bull. Earthq. Eng., 9, pp. 1067-1096, 2011. 
[47] Brando, G. et al., Structural survey and empirical seismic vulnerability assessment of dwellings in the historical centre of Cusco, Peru. Int. J. Archit. Herit., 3058, pp. 1-29, 2019.

[48] CISMID, Análisis de Riesgo en Zonas Urbanas del Distrito de Punta Negra, 2017. https://sigrid.cenepred.gob.pe/sigridv3/storage/biblioteca//6994_analisis-de-riesgoen-zonas-urbanas-del-distrito-de-punta-negra.pdf.

[49] Matsuzaki, S. et al., Evaluation of seismic vulnerability of buildings based on damage survey data from the 2007 Pisco, Peru earthquake. J. Disaster Res., 9, pp. 1050-1058, 2014.

[50] Santa-Cruz, S. et al., Social sustainability dimensions in the seismic risk reduction of public schools: A case study of Lima, Peru. Sustain. Sci. Pract. Policy., 12, pp. 34-46, 2016.

[51] Jena, R. et al., Integrated model for earthquake risk assessment using neural network and analytic hierarchy process: Aceh province, Indonesia. Geosci. Front., 11, pp. 613$634,2020$.

[52] Izquierdo-Horna, L. \& Kahhat, R., An interdisciplinary approach to identify zones vulnerable to earthquakes. Int. J. Disaster Risk Reduct., 48, 101592, 2020. 